\title{
Study on catalytic pyrolysis and efficient gasification of cellulose as biomass samples
}

\author{
Q. Wang ${ }^{1}$, T. Watanabe ${ }^{1}$, R. Ogawa ${ }^{1}$, P. Aparu ${ }^{1} \&$ K. Sugiyama ${ }^{2}$ \\ ${ }^{1}$ Graduate School of Science and Engineering Saitama University, Japan \\ ${ }^{2}$ Hachinohe National College of Technology, Japan
}

\begin{abstract}
Fossil fuels such as petroleum and coal will be exhaustible energy resources in the near future. From the point of view of the depletion of fossil resources, the development of renewable resources is required for a future sustainable society. Therefore, in recent years, renewable biomass, which is ubiquitous throughout the world, has attracted attention. Many studies on the application of waste woody biomass have been focused on non-edible biomass. Pyrolysis and gasification technologies have been known as the effective energy conversion technologies of biomass because of the various gases production such as synthesis fuel gases and chemical basic compounds. In the pyrolysis process, gases, condensable hydrocarbons so-called "tar" and solid carbon contents namely "char" will be produced. During the subsequent gasification process, char will usually react with the gasifying agents at a high temperature of above $900^{\circ} \mathrm{C}$ to produce the synthesis gases. However, there are many problems caused from generated tar during the pyrolysis process such as clogging of the piping and corrosion in the reactor. In order to perform efficient pyrolysis and gasification, there is still less information about the catalytic method although it has been widely used. In this study, we investigated the influence of iron and potassium as the catalysts on the pyrolysis process and the gasification process using an impregnation method to introduce these catalysts into the cellulose samples which is the major component of woody biomass. From the pyrolytic results, it was shown that the production of char and yields of gases were increased with the tar decrease in the presence of the catalytic metal species. Potassium catalyst seemed to especially increase the char yields. It may be caused by the decrease of crystal characteristics of the cellulose in the presence of catalytic metal species. According to the results of the gasification, a lower
\end{abstract}


temperature for gasification from $800^{\circ} \mathrm{C}$ was found when an iron catalyst was introduced into the cellulose samples, whereas the higher temperature for gasification above $900^{\circ} \mathrm{C}$ was determined using the potassium catalyst introduced into the cellulose samples. Furthermore, with the help of the introduction of both potassium and iron catalysts, efficient pyrolysis and gasification were performed.

Keywords: biomass, pyrolysis and gasification technologies, cellulose, catalyst, impregnation method, char, tar.

\section{Introduction}

Currently, it is necessary to consume large amounts of fossil resources, such as petroleum and coal. However, it considered fossil resources will be exhausted in the near future because the reserves of fossil fuels are finite. Therefore, renewable resources for the creation of a sustainable society are required. Among the renewable resources, the utilization of ubiquitous and non-edible woody biomass has attracted attention all over the world.

Pyrolysis and gasification technology is one of the energy conversion technologies from renewable biomass. The gases obtained by the pyrolysis and gasification are mainly composed of $\mathrm{H}_{2}$ and $\mathrm{CO}$, so-called synthesis gases, and other gaseous hydrocarbons. The synthesis gases can be used as fuel and for further synthesis of ammonia, liquid fuel, methanol, chemical products and a variety of derivative products [1]. Pyrolysis and gasification technologies consist of two processes of pyrolysis and gasification reaction. The pyrolysis is a reaction where biomass is heated to thereby generate gaseous components (such as $\mathrm{H}_{2}, \mathrm{H}_{2} \mathrm{O}, \mathrm{CO}, \mathrm{CO}_{2}, \mathrm{C}_{\mathrm{m}} \mathrm{H}_{\mathrm{n}}$ ), liquid tar (condensable organic compounds) and solid residue (char and ash) in an inert atmosphere. Ash is the inorganic component (such as $\mathrm{Na}, \mathrm{Mg}, \mathrm{Al}, \mathrm{Si}, \mathrm{K}, \mathrm{Ca}$ and $\mathrm{Fe}$, etc.) contained in the biomass, and present as oxides and carbonates. Gasification is the reaction for generating further gas and ash by heating the char with a gasifying agent $\left(\mathrm{H}_{2} \mathrm{O}, \mathrm{CO}_{2}\right.$ or $\left.\mathrm{O}_{2}\right)$. Tar produced during pyrolysis causes problems, such as a lowering fluidity of the fluid medium and clogging of the piping and corrosion in the reactor. As a countermeasure, suppressing the generation of tar requires a high temperature of above $1100^{\circ} \mathrm{C}$ [2]. However, this method requires a large amount of energy. Generally, the catalytic method has been used for pyrolysis and gasification reaction to proceed at lower temperatures. In order to perform efficient pyrolysis and gasification, there is still less information about the catalytic method although the catalytic method has been widely used. As the catalysts, alkali and alkaline earth metals (AAEM), and the transition metal are used.

In this study, cellulose was used, which is a major component of waste woody biomass as the model compounds in order to investigate the effects of the metal catalyst during pyrolysis and gasification. In our experiment, AAEM metal catalysts such as potassium were especially selected since the high catalytic ability of AAEM species in biomass [3-5], and iron catalyst was also used because they are inexpensive and readily available. These metal catalysts used in this study, were introduced using an impregnation method to be highly dispersed 
in the cellulose. The purpose of this study is to investigate the effects of metal catalysts on the catalytic behavior during the pyrolysis and gasification reaction of the adjusted metal-impregnated cellulose.

\section{Materials and methods}

\subsection{Materials}

We used $\alpha$-cellulose (Sigma-Aldrich Co. LLC., U.S.A) as a model compound of waste woody biomass, and the chemicals of iron (III) nitrate nonahydrate and potassium carbonate (Wako, Pure chemicals, Co. Ltd., Japan) used as the metal catalysts. Potassium and iron metal catalysts were introduced into the cellulose by the impregnation method. The operation of the impregnation method is described in the following procedure. Cellulose samples were added and mixed with the aqueous solution containing the amount of $0.5 \mathrm{wt} \% \mathrm{Fe}$ or $\mathrm{K}$. Then it was thoroughly dried at about $70^{\circ} \mathrm{C}$. A cellulose sample impregnated only iron (III) nitrate nonahydrate was expressed as Fe-cellulose, and only potassium carbonate was expressed as $\mathrm{K}_{2} \mathrm{CO}_{3}$-cellulose. Cellulose samples were impregnated and both metals were expressed as $\mathrm{Fe}=\mathrm{K}_{2} \mathrm{CO}_{3}$-cellulose. The gasification experiments were used and char obtained by these adjusted samples was thermally pyrolyzed. The utimate analysis of each sample char was carried out by a CHN corder (Model MT-5; Yanaco Co. Ltd., Japan). The results of the ultimate analysis of cellulose and char samples obtained by pyrolysis of each metal catalyst impregnated cellulose are shown in Table 1. Sulfur (S) and ash content of cellulose is set to zero because sulfur and ash in cellulose sample can be negligible.

Table 1: Ultimate analysis of cellulose and char samples obtained by pyrolysis of each metal catalyst impregnated cellulose.

\begin{tabular}{c|ccccc}
\hline$(\%)$ & cellulose & none-Char & $\mathrm{K}_{2} \mathrm{CO}_{3}-\mathrm{Char}$ & $\mathrm{Fe}-\mathrm{Char}$ & $\mathrm{Fe}=\mathrm{K}_{2} \mathrm{CO}_{3}-\mathrm{Char}$ \\
\hline $\mathrm{H}$ & 5.9 & 1.3 & 1.0 & 0.6 & 0.7 \\
$\mathrm{C}$ & 39.1 & 85.7 & 85.0 & 91.6 & 87.4 \\
$\mathrm{~N}$ & 0.0 & 0.1 & 0.1 & 0.1 & 0.0 \\
$\mathrm{O}$ & 54.9 & 13.0 & 13.8 & 7.7 & 11.8 \\
\hline
\end{tabular}

The crystal structure changes of each cellulose sample were analyzed using an X-ray diffractometer (XRD) due to introduce a metal catalyst is shown in Figure 1. Diffracted intensity is dependent on the sequence of the atoms and molecules. From these results, it considered that the crystallinity of cellulose samples were reduced by the introduction of metal catalysts.

\subsection{Behavior of cellulose during pyrolysis and gasification using the thermogravimentric differential thermal analysis (TG-DTA)}

The thermogravimetric differential thermal analysis (TG-DTA) (Model DTG-60; Shimadzu Co. Ltd., Japan) is used for analysis of both the thermogravimetric 
analysis (TGA) and the differential thermal analysis (DTA) simultaneously. The TGA analysis is a method of continuously measuring the weight decay of the sample upon heating or cooling of the sample while varying samples in accordance with a certain program (heating temperature, heating rate, gas flow rate). It is used to detect the physical changes such as evaporation and adsorption, and chemical changes such as dehydration, decomposition, oxidation and reduction. Furthermore, this thermal change is detected by the thermocouple inside the TGA device. It is possible to detect changes in decomposition, redox, adsorption and evaporation of the sample.

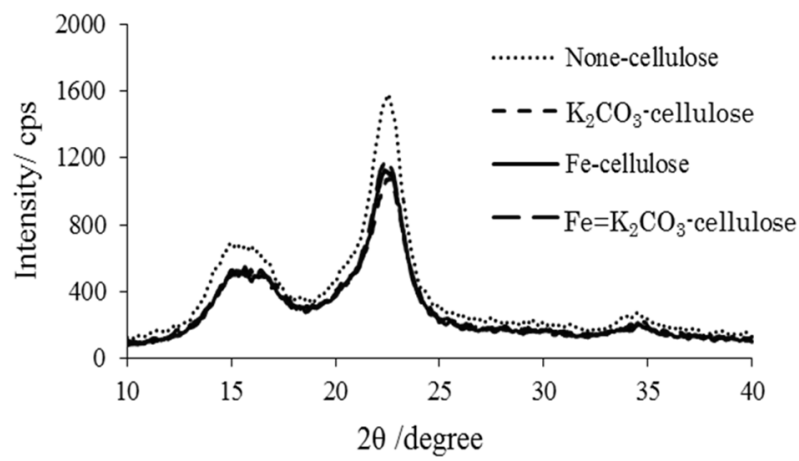

Figure 1: Diffracted intensity profiles of each cellulose samples.

\subsubsection{Pyrolysis behavior of cellulose samples}

The pyrolysis of each sample was carried out using thermogravimetric differential thermal analysis (TG-DTA). The initial weight of each sample was about $10 \mathrm{mg}$. Under a $\mathrm{CO}_{2}$ atmosphere, each sample was heated to $950^{\circ} \mathrm{C}$ by a heating rate of $5^{\circ} \mathrm{C} / \mathrm{min}$. The conversion rate $(\mathrm{x})$ was calculated from the weight loss measured using the TG-DTA and the initial weight. Weight loss was obtained from the conversion rate divided by the initial weight. The rate of the weight losses vs. time was expressed as $\mathrm{d} x / \mathrm{d} t$.

\subsubsection{Gasification behavior of cellulose char samples}

The gasification of each char sample was performed using the TG-DTA under the same conditions as pyrolysis $\left(\mathrm{CO}_{2}\right.$ atmosphere, heating rate of $5^{\circ} \mathrm{C} / \mathrm{min}$, up to $950^{\circ} \mathrm{C}$ ), and each char sample was obtained by the pyrolysis of each metal catalyst impregnated cellulose. In this condition, gasification of each char sample carried out at high temperatures of above $800^{\circ} \mathrm{C}$. Initial char weight when gasification of each sample started was not able to be unified, because char yield was different for each sample. It is needed to determine the initial char weight accurately. Considering this influence, pre-generated char was heated from the room temperature to $950^{\circ} \mathrm{C}$. The initial char weight was unified to about $5 \mathrm{mg}$ basis of carbon measured by the CHN coder (MT-5 Yanaco, Co. Ltd., Japan). 


\subsection{Measurement of the products obtained by pyrolysis of cellulose samples}

The experimental apparatus of pyrolysis and gasification is shown in Figure 2. Each cellulose sample was heated under $\mathrm{Ar}$ atmosphere by a heating rate of $10^{\circ} \mathrm{C} / \mathrm{min}$ from room temperature (about $25^{\circ} \mathrm{C}$ ) to $900^{\circ} \mathrm{C}$. The generated gases in the pyrolysis of each cellulose sample were measured every $80^{\circ} \mathrm{C}$ from $180^{\circ} \mathrm{C}$ to $820^{\circ} \mathrm{C}$. It was measured in major generated gases $\left(\mathrm{H}_{2}, \mathrm{CO}, \mathrm{CO}_{2}, \mathrm{CH}_{4}, \mathrm{C}_{2} \mathrm{H}_{4}\right.$, $\mathrm{C}_{2} \mathrm{H}_{6}, \mathrm{C}_{3} \mathrm{H}_{8}, \mathrm{C}_{3} \mathrm{H}_{6}, n-\mathrm{C}_{4} \mathrm{H}_{10}$, iso- $\mathrm{C}_{4} \mathrm{H}_{10}$ ) using a GC-TCD (GC-2010, Shimadzu Co. Ltd., Japan) and GC-FID (Model GC-2014, Shimadzu Co. Ltd., Japan). The yield of liquid tar generated during the pyrolysis of each cellulose sample, and was calculated from the difference between the weight change in the experiment before and after the tar trap shown in Figure 2. Tar contents are mainly present as "light tar" and "heavy tar" contents, considered the light tar is collected in the tar trap and the heavy tar remained in the reaction tube. There was a need to measure the moisture content of tar using a Karl Fischer moisture measuring instrument, because the trapped tar included water.

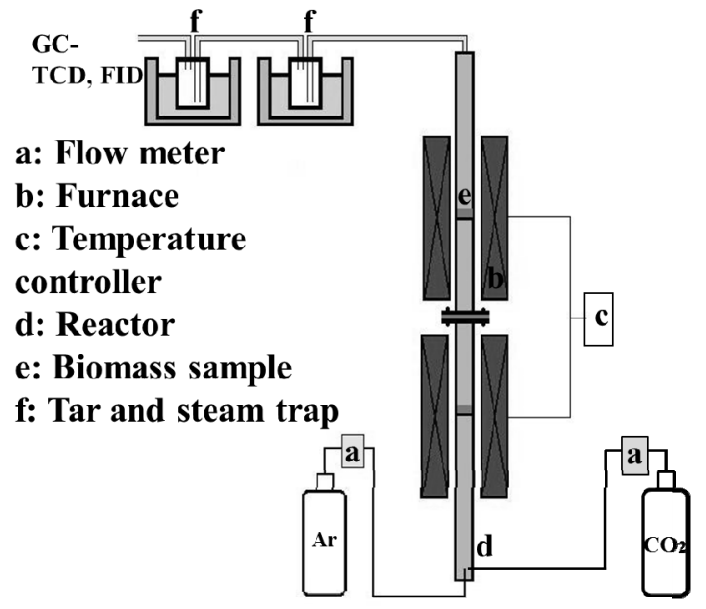

Figure 2: Experimental apparatus of pyrolysis and gasification.

\subsection{Measurement of gaseous products obtained by gasification of char samples}

Measurement of gaseous products obtained by gasification of each char sample was carried out using the experimental apparatus of pyrolysis and gasification shown in Figure 2. Each char sample was firstly heated by the heating rate of $10^{\circ} \mathrm{C} / \mathrm{min}$ from $25^{\circ} \mathrm{C}$ to $850^{\circ} \mathrm{C}$ under $\mathrm{Ar}$ atmosphere, and then held at $850^{\circ} \mathrm{C}$. Finally, the gasification reaction is started by introducing $\mathrm{CO}_{2}$. The gaseous contents generated by gasification of each char sample was analyzed every 5 to 60 minutes by a GC-TCD mentioned in above Section 2.2. We calculated the theoretical amount of $\mathrm{CO}_{2}$ gas from the introduction presumptive amount $\mathrm{CO}_{2}$ gas introduction amount was constantly supplied during gasification of each char sample. 


\section{Results and discussions}

\subsection{Pyrolysis behavior of various cellulose samples}

The weight decay of each cellulose sample during the pyrolysis reaction changing with the temperature were simultaneously measured using a TG-DTA to investigate the pyrolysis behavior cellulose impregnated with catalytic metals. All of the cellulose samples were thermally pyrolyzed to $950^{\circ} \mathrm{C}$ by a heating rate of $5^{\circ} \mathrm{C} / \mathrm{min}$ in $\mathrm{CO}_{2}$ atmosphere. The reaction of pyrolysis of cellulose is basically an endothermic reaction. The TG-DTA pyrolysis profiles that are weight losses and differential thermal analysis vs. time of different cellulose samples are shown in Figure 3. The major weight loss during pyrolysis of each cellulose sample was observed; $350^{\circ} \mathrm{C}$ was the same with literature values [6]. Furthermore, an endothermic reaction was found from the TG-DTA pyrolysis profiles at the same temperature range. It was considered that weight loss tendencies of all cellulose samples at around $800^{\circ} \mathrm{C}$ are the reaction of char and $\mathrm{CO}_{2}$ namely the Boudouard reaction [7]. The Boudouard reaction is the equilibrium reaction shown in reaction equation (1). The equilibrium reaction forward to produce $\mathrm{CO}$ usually occurs at high temperatures.

$$
\mathrm{C}+\mathrm{CO}_{2} \leftrightarrow 2 \mathrm{CO} \text { (Boudouard reaction) }
$$

In Figure 3(c) and (d), it was shown that the beginning temperature of gasification of Fe-cellulose and $\mathrm{Fe}=\mathrm{K}_{2} \mathrm{CO}_{3}$-cellulose was lower than $800^{\circ} \mathrm{C}$, which is also consistent with the literature [8].
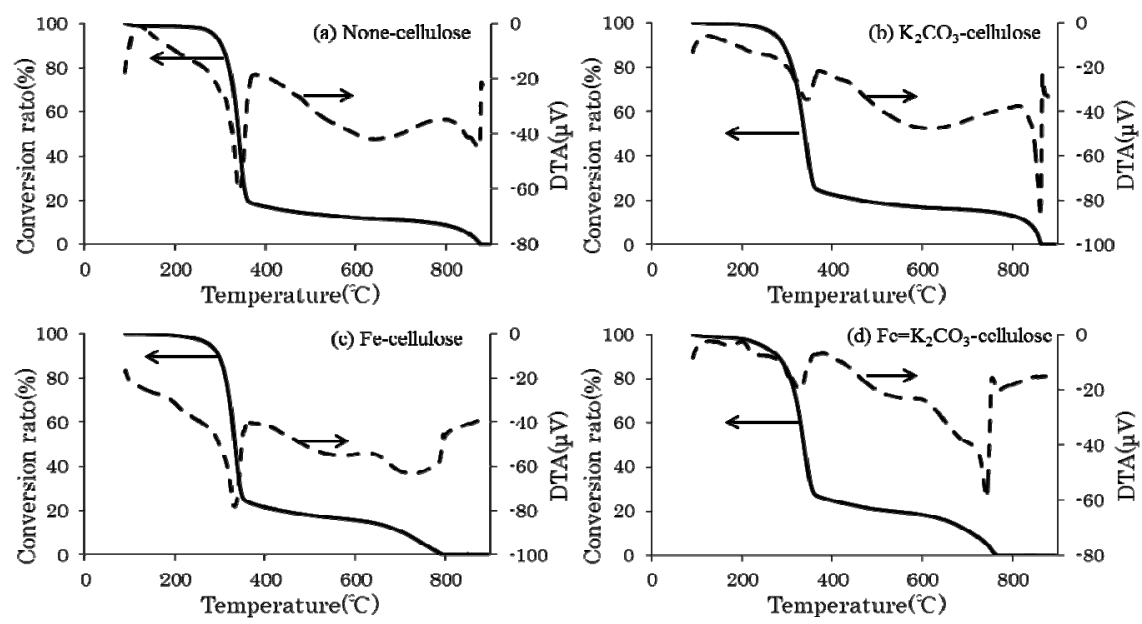

Figure 3: Pyrolysis profiles by the TG-DTA for different samples: (a) Noncellulose, (b) $\mathrm{K}_{2} \mathrm{CO}_{3}$-cellulose, (c) Fe-cellulose and (d) $\mathrm{Fe}=\mathrm{CO}_{3}$ cellulose. 
From the profiles of pyrolysis given in Figure 3, the weight loss due to pyrolysis occurring in the temperature range of $250-450^{\circ} \mathrm{C}$ can be considerable. Therefore, we have to investigate the pyrolysis behavior in the temperature range of $250-450^{\circ} \mathrm{C}$. The rate of the weight losses vs. time of different cellulose samples are given in Figure 4. It was found that the existence or absence of metal catalysts had little effect on the behavior of pyrolysis. The char yield and the temperature of each sample at the peak rate of the weight losses vs. time and DTA are shown in Table 2. It indicates the residue rate at the temperature of $600^{\circ} \mathrm{C}$ with the weight decay. The yield of char tended to rise only when impregnated with metals. It was believed that the difference in the yield of char occurred by the effect on the crystalline structure of cellulose by impregnating the metal. It was reported that the production amount of char increased by partial inhibition of cellulose depolymerization as the chemical bonding with $\mathrm{Fe}$ compound [9]. The increment in the char yield was also promoted by the polymerization reaction as the chemical bonding with $\mathrm{K}$ compound [8]. Thus, it is believed that the char produced will be increased by introducing the catalytic metals. Although there were no obvious changes in the reactivity of the pyrolysis by metal impregnation, it was still suggested that there are catalytic effects on the products such as char, tar and gases by metal impregnation.
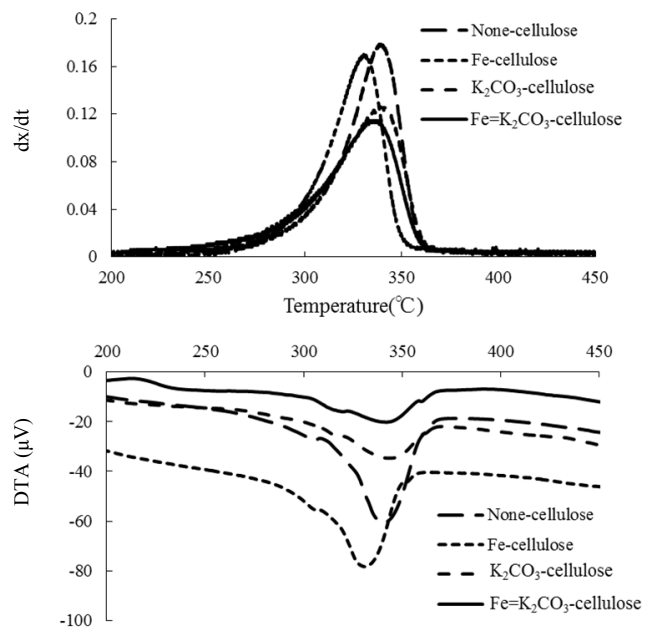

Figure 4: The rate of the weight losses vs. time $(\mathrm{dx} / \mathrm{dt})$ and DTA profiles during the pyrolysis of each cellulose sample.

\subsection{Gasification behavior of cellulose char samples}

Pre-generated char samples of cellulose were heated in $\mathrm{CO}_{2}$ atmosphere to $950^{\circ} \mathrm{C}$ by a heating rate of $5^{\circ} \mathrm{C} / \mathrm{min}$. As given in Figure 5, it was found that the peaks resulted in gasification profiles of $\mathrm{K}_{2} \mathrm{CO}_{3}$-char being shifted to the lower temperature range of about $30^{\circ} \mathrm{C}$ then the original cellulose char without catalytic metal introduction expressed as "non-char" in Figure 5. With $\mathrm{CO}_{2}$ 
gasification reactivity of $\mathrm{Fe}-\mathrm{Char}$ and $\mathrm{Fe}=\mathrm{K}_{2} \mathrm{CO}_{3}$-Char it was confirmed that the weight decay occurred in two stages. From the results of DTA profiles, it was thought that the reduction may be caused by char gasification (Boudouard reaction) and the iron oxide because both reactions were an endothermic reaction. The catalytic effect of $\mathrm{Fe}=\mathrm{K}_{2} \mathrm{CO}_{3}$ was better than other. The combination of iron and potassium seems to be the better performance in gasification at the lower temperatures.

Table 2: $\quad$ The comparison of char yield at $600^{\circ} \mathrm{C}$ and the temperature of each cellulose sample at the peak of $\mathrm{d} x / \mathrm{d} t$ and DTA.

\begin{tabular}{c|cccc}
\hline & None-cellulose & $\mathrm{K}_{2} \mathrm{CO}_{3}$-cellulose & Fe-cellulose & $\mathrm{Fe}=\mathrm{K}_{2} \mathrm{CO}_{3}$-cellulose \\
\hline DTA $\left({ }^{\circ} \mathrm{C}\right)$ & 340.2 & 344.6 & 332 & 342.1 \\
$\mathrm{dx} / \mathrm{dt}\left({ }^{\circ} \mathrm{C}\right)$ & 338.1 & 339.1 & 330 & 333.5 \\
Char yields $(\%)$ & $16.2 \pm 1.0$ & $21.5 \pm 0.3$ & $21.9 \pm 0.6$ & $24.1 \pm 0.6$ \\
\hline
\end{tabular}
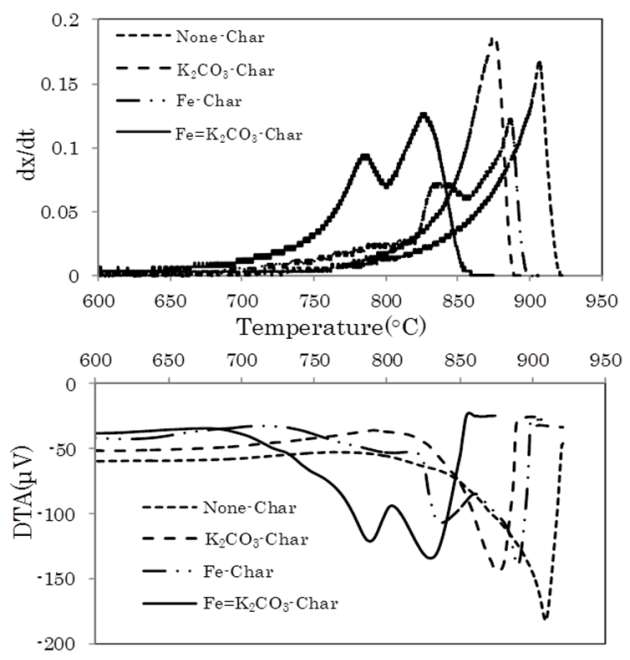

Figure 5: $\quad$ TG-DTA profiles during gasification of each char sample.

\subsection{Gases and tar yields obtained by pyrolysis of cellulose samples}

From the results of the pyrolysis by a TG-DTA, it was suggested that impregnation of metal catalyst contributes to the yield of pyrolysis products. We measured the gases and tar contents generated by pyrolysis using the apparatus shown in Figure 1. Each sample was heated in Ar atmosphere from a room temperature of about $25^{\circ} \mathrm{C}$ to $820^{\circ} \mathrm{C}$ by a heating rate of $10^{\circ} \mathrm{C} / \mathrm{min}$. The generated gases from pyrolysis were analyzed every $80^{\circ} \mathrm{C}$ from $180^{\circ} \mathrm{C}$ by $\mathrm{GC}$ TCD and GC-FID detectors. 
The results of product yields obtained by pyrolysis and gaseous profiles are shown in Figure 6 and Figure 7, respectively. "Others" in these figures indicate heavy tar and soot or so-called "coke" remaining in the reaction tube and gas which are unmeasurable. Soot is formed from volatile carbonate components during pyrolysis. Neither amount of product by metal impregnation changed dramatically. But a tendency to yield of the product volume of the char and the product gas associated with the reduction of tar by metal impregnation increases were observed. In particular, there was a possibility to shift to the char from tar so that the proportion of tar and char hardly changed. In addition, the proportion of others in Figure 6 had been reduced by about 10\% due to the presence of $\mathrm{K}$. This result suggested the possibility that $\mathrm{K}$ can reduce problems due to tar. The inhibitory effect of the route to be tar is considered to be high (especially heavy tar) due to the pyrolysis pathway of cellulose being modified by metal. This effect was suggested towards $\mathrm{K}$ that $\mathrm{Fe}$ is more effective. It was confirmed that $\mathrm{CO}$ and $\mathrm{CO}_{2}$ are generated before and after temperature of $350^{\circ} \mathrm{C}$ because of the peak weight loss in the TG-DTA profiles. In the pyrolysis of cellulose it was confirmed that the two gases are the main products. In this study, $\mathrm{K}$ in the thermal decomposition of cellulose compared to $\mathrm{Fe}$, a high potential to contribute to the char product, and it is suggested that the higher inhibitory will have an effect on the path of heavy tar production. The gaseous contents were observed even at the temperature range of $450-600^{\circ} \mathrm{C}$ that weight decay almost did not occur. This is considered to be attributed to the secondary tar decomposition.
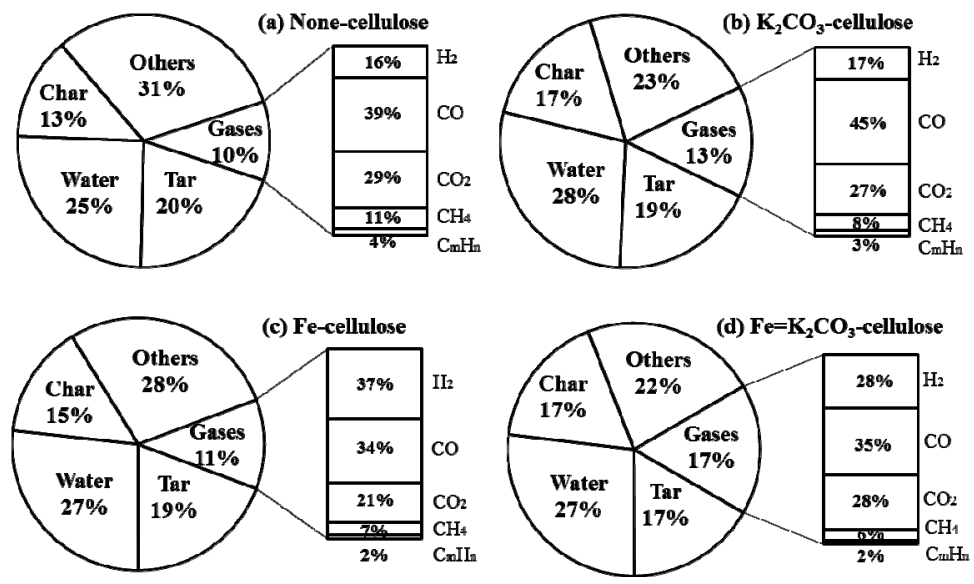

Figure 6: The component yields during pyrolysis of different samples. Here,
(a) Non-cellulose,
(b) $\mathrm{K}_{2} \mathrm{CO}_{3}$-cellulose,
(c) Fe-cellulose and
(d) $\mathrm{Fe}=\mathrm{K}_{2} \mathrm{CO}_{3}$-cellulose. $\mathrm{C}_{\mathrm{m}} \mathrm{H}_{\mathrm{n}}$ means hydrocarbons such as $\mathrm{C}_{2} \mathrm{H}_{4}$, $\mathrm{C}_{2} \mathrm{H}_{6}, \mathrm{C}_{3} \mathrm{H}_{8}, \mathrm{C}_{3} \mathrm{H}_{6}, n-\mathrm{C}_{4} \mathrm{H}_{10}$, iso- $\left.\mathrm{C}_{4} \mathrm{H}_{10}\right)$. 

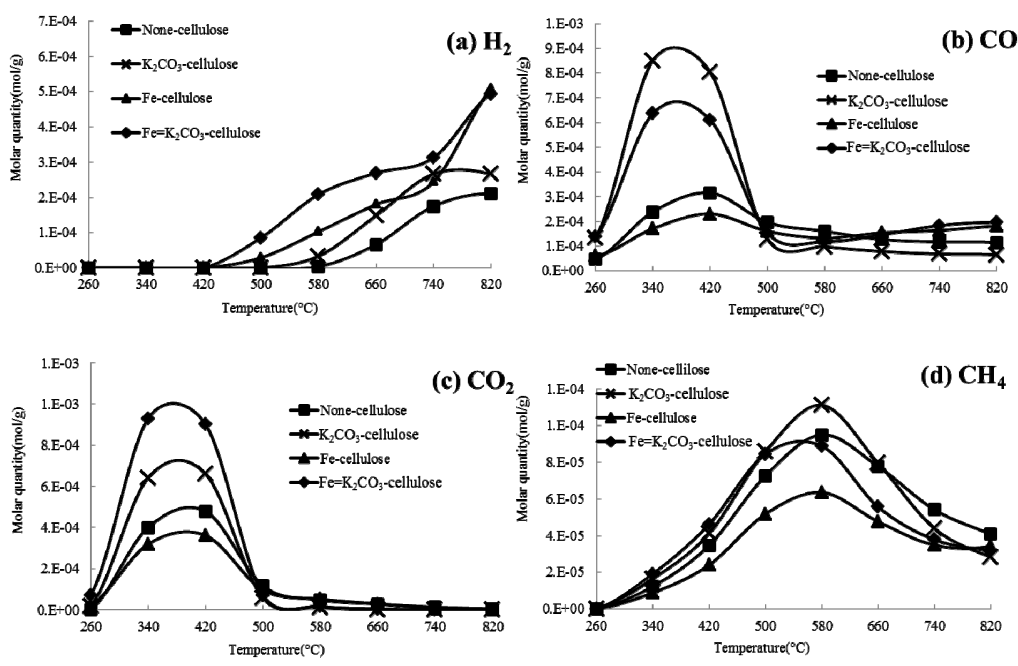

Figure 7: Gas profiles generated by pyrolysis of each sample: (a) $\mathrm{H}_{2}$, (b) $\mathrm{CO}$, (c) $\mathrm{CO}_{2}$ and (d) $\mathrm{CH}_{4}$.

\subsection{Product gases yields obtained by gasification of char samples}

The gasification profiles of $\mathrm{Fe}=\mathrm{K}_{2} \mathrm{CO}_{3}$-cellulose and Fe-cellulose were shown in Figure 3. We carried out gasification of $\mathrm{Fe}=\mathrm{K}_{2} \mathrm{CO}_{3}$-char and $\mathrm{Fe}$-char. The initial weight of $0.100 \mathrm{~g}$ char on the carbon basis was adjusted in each char sample as decided by the $\mathrm{CHN}$ coder. After heating in an Ar atmosphere at a heating rate of $10^{\circ} \mathrm{C} / \mathrm{min}$ from a room temperature of about $25^{\circ} \mathrm{C}$ to $850^{\circ} \mathrm{C}$, and having started $\mathrm{CO}_{2}$ gasification by the introduction of $\mathrm{CO}_{2}$ gas, Figure 8 shows the profiles of $\mathrm{CO}$ and $\mathrm{CO}_{2}$ yields on each occasion. Here, Boudouard equilibrium reaction progressed forward to produce $\mathrm{CO}$ as given in reaction equation (1). Since the $\mathrm{CO}$ generation needed to consume $\mathrm{CO}_{2}$ during the gasification, $\mathrm{CO}$ yields were highly increased up to 30 minutes. As shown in Figure 8, it was found that $\mathrm{CO}$ yields of Fe-char gasification were higher than those of $\mathrm{Fe}=\mathrm{K}_{2} \mathrm{CO}_{3}$-char. Therefore, the activity of Fe-char seemed to be higher than that of $\mathrm{Fe}=\mathrm{K}_{2} \mathrm{CO}_{3}$ char. However, the real activity of $\mathrm{Fe}=\mathrm{K}_{2} \mathrm{CO}_{3}$-char was not expected to be as high as the results of gasification at a high temperature using the TG-DTA.

It is considered that atomic oxygen $(\mathrm{O})$ in the gasifying agent be adsorbed onto the metal in the char during gasification. The adsorbed atomic $\mathrm{O}$ reacts with the close of atomic carbon (C), and then the gasification will be progressed [10]. The mechanism of catalytic metal $\mathrm{CO}_{2}$ gasification of char is given from the following reaction equation (2) to equation (4) [11].

$$
\begin{aligned}
\mathrm{MO}+\mathrm{CO}_{2} & \rightarrow \mathrm{MO}(\mathrm{O})+\mathrm{CO} \\
\mathrm{MO}(\mathrm{O})+\mathrm{C}_{\mathrm{f}} & \rightarrow \mathrm{MO}+\mathrm{C}(\mathrm{O}) \\
\mathrm{C}(\mathrm{O}) & \rightarrow \mathrm{CO}
\end{aligned}
$$


In these reaction equations, $M$ means a catalytic atomic metal, $\mathrm{C}_{\mathrm{f}}$ and $\mathrm{C}(\mathrm{O})$ represent an active carbon site and a carbon-oxygen complex, respectively. The catalytic metals can increase the gasification reactivity of char by their catalytic effect.

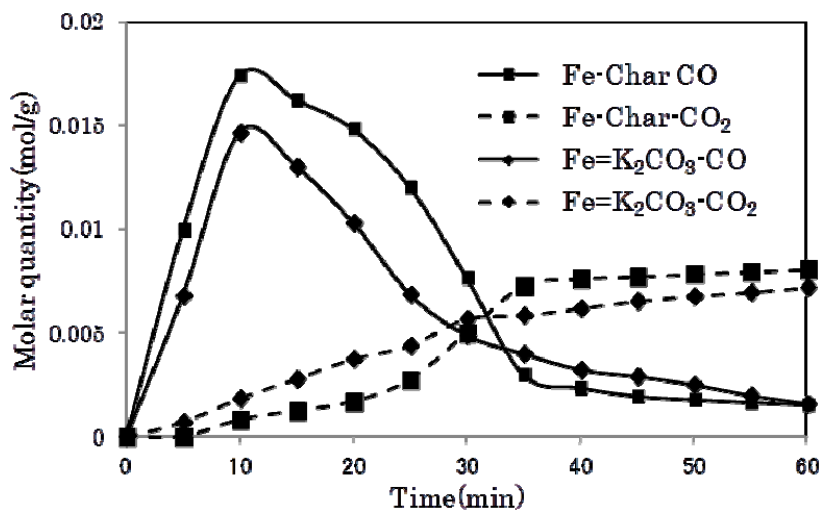

Figure 8: The profiles of $\mathrm{CO}$ and $\mathrm{CO}_{2}$ yields during $\mathrm{CO}_{2}$ gasification.

During the gasification of different char samples under a constant temperature of $850^{\circ} \mathrm{C}$, the higher catalytic effect was found only for iron in a Fe-cellulose char sample. That is, the higher catalytic effect of Fe was determined than that of $\mathrm{Fe}$ and $\mathrm{K}$ mixed catalysts. It was considered that $\mathrm{Fe}$ as a metal catalyst may lead to a better catalytic effect because it will keep its reaction site during the gasification. On the other hand, when both $\mathrm{K}$ and $\mathrm{Fe}$ are present, it was found that the catalytic effect of $\mathrm{K}$ decreased since its activity may be less at the high temperature of $850^{\circ} \mathrm{C}$.

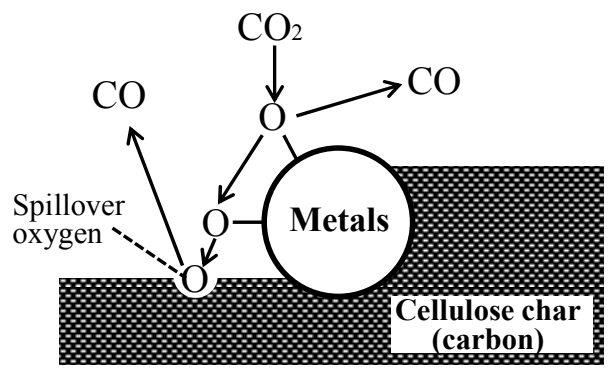

Figure 9: Mechanism of catalytic metals for carbon gasification.

\section{Conclusion}

Differences in pyrolysis and gasification by metal species appeared by impregnating the metal to the cellulose. In the case of introducing catalytic metals to cellulose, the trend of increase of char yield and reduction of heavy tar was found. This effect was especially noticeable in $\mathrm{K}_{2} \mathrm{CO}_{3}$-cellulose and $\mathrm{Fe}=\mathrm{K}_{2} \mathrm{CO}_{3}$-cellulose. The increase in char formation of cellulose during catalytic 
$\mathrm{K}$ pyrolysis can be considered. However, in constant gasification at $850^{\circ} \mathrm{C}$, it was suggested that its reactivity is reduced due to less activity of catalytic $\mathrm{K}$. The gasification of $\mathrm{Fe}$ had higher reactivity under these gasification conditions. However, it found that high char yields and relatively high gasification reactivity can be obtained by a combination of $\mathrm{Fe}$ and $\mathrm{K}$. The results and information from this study may be useful for the effective energy conversion technologies of biomass.

\section{Acknowledgement}

Some work of this study is supported by the Special Funds for Basic Research (B) (No. 19404021, FY2007-FY2009, No. 22404022, FY2010-FY2012 and No. 15H05119, FY2015-FY2017) of the Japanese Ministry of Education, Culture, Sports, Science and Technology (MEXT), Japan.

\section{References}

[1] Lin, S. World gasification process development for syngas production. Journal of the Japan Institute of Energy, 91, pp. 826-834, 2012

[2] Zhang, R., Brown, R.C., Suby, A. \& Cummer, K. Catalytic destruction of tar in biomass derived producer gas. Energy Conversion and Management, 45, p. 995, 2004.

[3] N. Shimada et al. J. Anal. Appl. Pyrolysis, Different action of alkali/alkaline earth metal chlorides on cellulose pyrolysis, 81, pp. 80-87, 2008.

[4] K. Yip et al. Effect of alkali and alkaline earth metallic species on biochar reactivity and syngas compositions during steam gasification, Energy Fuels, 24, pp. 173-181, 2010.

[5] Q. Wang, et al. Study on heterogeneous reaction between tar and ash from waste biomass pyrolysis and gasification. WIT Transactions on Ecology and the Environment, 176, Energy and Sustainability IV, 291-302, 2013.

[6] Yang, Y. et al. Characteristics of hemicellulose, cellulose and lignin pyrolysis, Fuel, 86, pp. 1781-1788, 2007.

[7] D. Sutton, B. Kelleher, Julian R.H. Ross, Review of literature on catalysts for biomass gasification, Fuel Processing Technology, 73, pp. 155-173, 2001.

[8] Daniel, J., et al. Uncatalysed and potassium-catalysed pyrolysis of the cellwall constituents of biomass and their model compounds, Journal of Analytical and Applied Pyrolysis, 83, pp. 12-25, 2008.

[9] Francois-Xavier, C. et al. Influence of impregnated metal on the pyrolysis conversion of biomass constituents, Journal of Analytical and Applied Pyrolysis, 95, pp. 213-226, 2012.

[10] Tomita, A., Catalysis of carbon-gas reactions, Catalysis Surveys from Japan, 5, pp. 17-24, 2001.

[11] Q. Wang, et al. Reactivity for pyrolysis and $\mathrm{CO}_{2}$ gasification of alkali metal loaded waste wood char, Int. J. Sus. Dev. Plann. 9, pp. 705-716, 2014. 